\title{
Being more conscientious, collaborative, and confident in addressing patients' fears and anxieties: nurses' perspectives
}

This article was published in the following Dove Press journal:

Nursing: Research and Reviews

17 August 2013

Number of times this article has been viewed

\author{
Susan E Beswick' \\ Sandee Westell' \\ Sarah Sweetman' \\ Charmaine Mothersill' \\ Lianne P Jeffs ${ }^{1,2}$ \\ 'St Michael's Hospital, Toronto, ON, \\ Canada; ${ }^{2}$ Keenan Research Centre of \\ the Li Ka Shing Knowledge Institute, \\ St Michael's Hospital, Toronto, ON, \\ Canada
}

Background: Developing a therapeutic partnership between patient and nurse is key to ensuring the patient's needs and preferences are identified, addressed, and valued as a key patient safety goal. There is growing recognition that patients living with chronic lung diseases often experience increased levels of stress, anxiety, and depression compared to their healthy counterparts. Creating strategies for early identification and management of patients' fears and anxieties is a strategy to minimize anxiety and depressive symptoms.

Methods: This article provides an overview of a qualitative study which explored nurses' perceptions and experiences associated with the implementation of the Registered Nurses' Association of Ontario's Establishing Therapeutic Relationships Best Practice Guideline that focused on strategies to alleviate patients' fears and anxieties on one respirology unit.

Results: Study findings suggest that involvement in Best Practice Guideline implementation enabled nurses to address patients' fears and anxieties in a focused, conscientious manner and to be more collaborative and confident in their care.

Conclusion: Providing opportunities for nurses to learn and apply evidence-based practice around therapeutic patient-centered care is a key step in ensuring a quality patient experience. Keywords: evidence-based practice, best practice guideline, therapeutic relationship, fear and anxiety, collaborative practice

\section{Background}

Developing a therapeutic partnership between patient and nurse is key to ensuring the patient's needs and preferences are identified, addressed, ${ }^{1}$ and valued as a key patient safety goal. ${ }^{2-5}$ Through this therapeutic partnership, patients' perspectives of their care and needs are seen as a valuable source of information used to direct care delivery. ${ }^{6-9}$ Engaging patients living with chronic conditions or diseases in their care is important, as they are key information sources for care planning. These patients are particularly aware of, and know how to manage, deteriorating symptoms (eg, shortness of breath) and psychological responses (eg, anxieties and fears associated with deteriorating symptoms). Given their significant interactions with patients, nurses play an integral role in establishing therapeutic partnerships with patients. ${ }^{10}$ Effective nurse-patient therapeutic partnerships have been shown to enhance satisfaction with nursing care ${ }^{11}$ and quality of care. ${ }^{12,13}$

As psychological care of patients is becoming more prominent within health care, there is growing recognition that patients living with chronic lung diseases such as cystic fibrosis (CF) or chronic obstructive pulmonary disease often experience increased levels of stress, anxiety, and depression compared to their healthy counter-
Correspondence: Susan E Beswick St Michael's Hospital, Room 5050 Bond Wing, 30 Bond Street, Toronto, Ontario, M5B IW8, Canada

Tel + I $4 \mid 68646060$ ext 2270

Email beswicks@smh.ca 
parts. ${ }^{14,15}$ Studies have demonstrated that the CF population has few, if any, differences in anxiety, depression, and selfimage compared to non-CF patients under regular circumstances. ${ }^{16,17} \mathrm{CF}$ patients experience significant numbers of abnormal situations as a result of their disease process, and have an increased prevalence of anxiety and depression when compared to the general population. ${ }^{14}$ For example, in one study, young adults living with $\mathrm{CF}$ described experiencing anxiety associated with managing their $\mathrm{CF}$, their growth and development, and their family relations. ${ }^{18}$ Further, having a consistent caregiver coupled with frequent interactions provided patients the comfort and opportunity for disclosure of their problems and concerns. ${ }^{18}$

Given the frequent admissions many respirology patients experience, as well as the associated symptoms and treatments, creating strategies for the early identification of patients' fears and anxieties, and for addressing those feelings, is a strategy that may minimize anxiety and depressive symptoms. To this end, a respirology unit within a large academic health sciences teaching hospital in Toronto, Ontario, implemented the Registered Nurses' Association of Ontario's (RNAO) Establishing Therapeutic Relationships (ETR) Best Practice Guideline (BPG) as part of an organization-wide initiative. This article provides an overview of a study which explored nurses' perceptions and experiences of the implementation of the ETR guideline that focused on strategies to alleviate patients' fears and anxieties in one respirology unit.

\section{Methods}

\section{Intervention description}

In 2009, our 500-bed urban acute care academic health science center, located in Toronto, ON, Canada, began a 3-year journey in becoming an RNAO Best Practice Spotlight Organization (BPSO). As a part of a larger corporate nursing professional practice initiative, clinical units selected $\mathrm{BPG}(\mathrm{s})$ relevant to the practice area and patient population for implementation.

The respirology unit is a 15-bed unit which cares predominantly for patients with $\mathrm{CF}$, chronic obstructive pulmonary disease, hereditary hemorrhagic telangiectasia, and lung cancer. Length of stay varies on this unit; most patients are admitted for 14 days on average, with frequent readmissions due to the nature of their diseases. The nurses on the respirology unit chose to focus on addressing fears and anxieties of patients admitted to the unit, using the ETR BPG. They selected this as their focus because of the fluctuating course of this patient population's disease process, multiple admissions, and patient satisfaction survey scores identifying nurses addressing patients' fears and anxieties as an area for improvement.

All full- and part-time nursing staff attended a structured, interactive education session where components of therapeutic relationships and the importance of engaging with patients therapeutically were discussed. Nurses were informed of patient survey results which identified key causes of fears and anxieties (eg, separation from home, receiving new health information, and meeting new health care providers). Following the education session, the expectation was for all nursing staff to ask patients about their fears and anxieties and document these as psychosocial concerns, both on the nursing care plan and in the interdisciplinary notes on the patient's electronic chart. The initial education session was supplemented with a booster session 6 months following initial implementation, as well as room signs to cue patients to engage in discussions with nurses. The nurse manager provided in-service education to all members of the health care team (physicians and allied health) to inform them of this practice change. Posters and pocket reminder cards were created and distributed to all staff.

\section{Design and procedures}

A qualitative study was undertaken to gain insight into nurses' experiences associated with the implementation of a BPG, which was aimed at enhancing nurse-patient therapeutic relationships through identifying and addressing patients' fears and anxieties. St Michael's Hospital research ethics board approval was obtained. All registered nurses working on the respirology unit were eligible to participate. A total of 11 registered nurses were interviewed (Table 1); the demographics of those who participated were representative of the cohort of nurses employed on the unit. A return of findings focus group was held with nursing staff in which three nurses attended (Table 2), representing a variety of experience levels. Focus group members were not required to have participated in initial interviews; this focus group was used as a method of member-checking to validate study findings. All participants were female.

Table I Nurse interview participant demographics

\begin{tabular}{ll}
\hline Years in organization $(\mathbf{n})$ & Years in current role (n) \\
\hline Less than 5 years (4): $36 \%$ & Less than 5 years $(6): 55 \%$ \\
$5-10$ years (2): $18 \%$ & $5-10$ years (2): $18 \%$ \\
II-20 years (3): $27 \%$ & II-20 years (3): $27 \%$ \\
More than 20 years (2): $18 \%$ &
\end{tabular}

Note: All values are rounded to the nearest $1 \%$. 
Table 2 Return of findings focus group participant demographics

\begin{tabular}{|c|c|c|}
\hline $\begin{array}{l}\text { Total years } \\
\text { nursing (n) }\end{array}$ & $\begin{array}{l}\text { Years in current } \\
\text { role (n) }\end{array}$ & $\begin{array}{l}\text { Educational } \\
\text { preparation (n) }\end{array}$ \\
\hline $5-10$ years $(1): 33 \%$ & $\begin{array}{l}\text { Less than } 5 \text { years } \\
\text { (I): } 33 \%\end{array}$ & $\begin{array}{l}\text { Nursing diploma } \\
\text { (2): } 67 \%\end{array}$ \\
\hline II-20 years (I): 33\% & $5-10$ years $(1): 33 \%$ & \\
\hline $\begin{array}{l}\text { More than } 20 \text { years } \\
\text { (I): } 33 \%\end{array}$ & $\mathrm{II}-20$ years $(\mathrm{I}): 33 \%$ & $\begin{array}{l}\text { Bachelor of Science } \\
\text { in nursing (I): } 33 \%\end{array}$ \\
\hline
\end{tabular}

Note: All values are rounded to the nearest 1\%.

The interview guide was pilot-tested for face validity with seven members of the hospital's BPSO steering committee. In order to recruit participants, the nurse manager and resource nurse were contacted to arrange days to conduct interviews. Nurses scheduled to work on those days were initially approached by the nurse manager or resource nurse who provided an overview of the study. For those nurses who were interested in participating, an interview was scheduled with one of the research assistants. To address the potential for coercion, prior to the interview being started, the research assistant provided an overview of the study and informed participants that they were able to not participate or withdraw at any time, and that the nurse manager/resource nurse would not be informed of who participated or not. Interviews were conducted between June-August 2011 by two research assistants who were trained by the principal investigator (PI), an experienced qualitative researcher, in order to ensure consistency.

The recruitment process for the return of findings focus group involved nurses being approached by their nurse manager for participation based on who was scheduled to work on the day the focus group was scheduled. The study was explained by the research coordinator. The focus group was conducted in November 2011 by a research coordinator with previous experience conducting interviews and additional training by the PI. No new data emerged during the return of findings session. Written informed consent was obtained from all participants in this study.

All interviews were audiotaped and transcribed for analysis. Data were analyzed using a directed content analysis approach. Specifically, our analytical process included three investigators reviewing all transcripts independently, line by line, to identify sections of text which served as codes and were then rolled up into categories. Next, the investigators met to achieve consensus on codes and categories. During this analytical step, codes and categories were grouped to form overall themes. As a cross-checking measure, the PI reviewed all transcripts to ensure all categories and themes were captured in the final coding schema.

\section{Results}

Two key themes emerged relating to nurses' experiences and perceptions associated with implementation of the ETR BPG from all interviews and focus groups conducted: (1) addressing patients' fears and anxieties in a focused, conscientious manner and (2) being more collaborative and confident.

\section{Addressing patients' fears and anxieties in a focused, conscientious manner}

The first theme reflects participants' descriptions of being more conscious of the care they are providing while simultaneously providing more thorough and focused care. Participants described being more conscious of both the importance of identifying and addressing patients' fears and anxieties, and of when they were actually doing this. Many participants described, prior to BPG implementation, how they were not necessarily recognizing that patients had fears or anxieties or the extent to which they were impacting on the patients. For some, despite having good relationships with patients, patients' fears or anxieties were not something they explored with them, while other nurses explained that they had been identifying and addressing patients' fears and anxieties but this discussion served to put a name to something they were already doing. The following two narrative excerpts demonstrate these points:

It makes you more conscious that you're actually doing these things, dealing professionally with your patients, and trying to be therapeutic in terms of their concerns. It makes me more conscious that I'm actually doing it because it's something we automatically do without putting a label on it. Now that they're bringing it up we're more conscious of it. [Registered Nurse 001]

It has reminded us, put it in the forefront to really address these therapeutic relations through anxiety and fears. To do it on your shift assessment, to do it on the admission assessment and just take the time and do a bit more exploring, and pass it on, update the Kardex, put it in report, just to be more accountable. [RN002]

By being more aware of the importance of identifying and addressing patients' fears and anxieties and the value it brings to patients, nurse participants described completing more focused and thorough assessments of their patients. Study participants explained that previously, fears and anxieties were assessed on an ad hoc basis. Nurses now directly ask patients about their fears and anxieties at regular intervals, and identify strategies they can implement to alleviate them. Care is more focused around the particular needs of an individual patient, and nurses have developed more in-depth 
assessment skills to identify any concerns. The following three narrative quotes illustrate this category:

It helped me with my assessment skills. They improved because it forced me to ask more questions and to gain more knowledge about that topic. It actually established a better rapport with my patients. [RN007]

When you establish a therapeutic relationship, part of that is establishing what it is that your client needs, or what they're concerned about. And that might not necessarily be what the doctors think, or what you may think. In learning more through the initiative about the therapeutic relationship you tend to really focus your care specifically to your specific patient. [RN004]

One of our patients was going home on home IV and he had concerns about the nurses in the community and their technique for accessing his port. I asked the social worker to come in with me while we speak to the patient and one of the CCAC [Community Care Access Center] coordinators so she could hear and give advice and speak to the homecare piece. And our social worker, myself, to sort of brainstorm, collaborate, work together to allay some of his fears and anxiety. [RN003]

\section{Being more collaborative and confident}

This second theme reflects participants describing their practice becoming more collaborative with nursing and nonnursing colleagues. Participants described two key collaborations which improved as a result of this work.

First, study participants explained that through the implementation of the ETR BPG, they are more aware of patients' fears and anxieties; they now share this knowledge with other health care team members so that all can contribute to addressing these needs. Nurses described previous practices where they may have become aware of a patient's fears and anxieties, but this information was inconsistently passed along and therefore was frequently missed. In contrast, study participants described now having a system in place to ensure this information was both recorded in a common area for all health care team members to see as well as verbally passed along to the incoming nurse. Study participants explained that this practice creates opportunity for patients' fears and anxieties to be better addressed by all members of their care team. Key to this was creating an environment where nurses felt more confident in collaborating with other disciplines. This is illustrated in the following narrative excerpts.

Part of the teaching was that we are to collaborate to refer patients to see other people. It's part of our responsibility and part of our professional practice. So I would say so I'm more aware. [RN003]

It's awareness and then being able to effectively communicate that information to other people. So if a patient says that I'm worried I'm going to die, the mission is finding a spot in the Kardex to put that down, and to let the team know so that those fears are addressed, and that it's not just left. [RN006]

At the beginning I was a little bit more timid. Now I feel that whenever I do get the information from my patients, I'm able to take it upon myself to find the specific person I need help from and bring it to their attention. [RN005]

Second, nurse participants described sharing their knowledge gained through BPG implementation. Participants explained that they discuss what they learned amongst themselves and share their learnings with other team members and nursing colleagues, both within and external to the organization. Participants also described sharing new knowledge gained with nursing students. Importantly, nurse participants described enhanced preceptorship abilities by promoting evidence-based practice (EBP) among nursing students. The following two narrative examples illustrate this.

I've shared it with the students that I've worked with. I've shared it with other team members. Whenever I hear something new, I always talk to the other team or even some of my other nurse friends from other floors. [RN005]

It has enhanced our preceptoring when we're speaking about these guidelines. It's really reminding [the students] and making them aware that the RNAO is always a part of this hospital and it is a part of your practice when you're nursing. [RN002]

\section{Discussion}

Our study findings suggest that being involved in the implementation of a BPG aimed at alleviating patients' fears and anxieties enhanced nurses' ability to provide care in a more focused, conscientious manner and led to their being more collaborative and confident when caring for this patient population. Study findings add to a growing body of evidence of the impact associated with the implementation of BPGs and specifically within the respirology clinical cohort.

Our themes of (1) addressing patients' fears and anxieties in a focused, conscientious manner and (2) being more collaborative and confident, are similar to a recent study which explored hemodialysis nurses' perceptions associated with implementation of RNAO's Assessment and Management of Foot Ulcers for People with Diabetes BPG. ${ }^{19}$ 
This study found that nurses engaged in enhanced patient assessments, focused on patients' individual care needs, and provided more preventative care. ${ }^{19}$ In our study, participants explained that a range of fears and anxieties this patient population may experience was not always considered and explored with patients, because nurses felt they already "knew" the patients since they saw them frequently and for extended admissions. Study participants described becoming more aware that a gap in care existed around acknowledging and alleviating fears and anxieties of CF patients. This, alongside the ability to hone assessment skills to address fears and anxieties, was attributed to implementation of the BPG. Our study findings are consistent with other research which has found that participating in embedding evidencebased practices into clinical care enhanced nurses' ability to provide more focused, collaborative care. ${ }^{19}$ A key component of establishing a therapeutic relationship with patients includes better involving them in their care and addressing their self-identified needs. This is linked to improved care quality and enhanced patient satisfaction, ${ }^{12,13}$ and is a key aspect of patient-centered care which recognizes the patients' needs and concerns, which may be unique from that of the medical perspective. ${ }^{1}$ Further, the importance of the patient experience as a means of shaping solutions and targeting practice improvements to enhance the quality and safety of care has become a valuable source of information. ${ }^{20,21}$

Study participants described sharing ongoing work with nursing and nonnursing colleagues, both internal and external to the organization. This finding is important and adds to other research that links engaging nurses in EBP implementation with nurses' enhanced sense of professionalism. ${ }^{22,23}$ Nurses also described that participating in BPG implementation enhanced their teaching and interactions with undergraduate nursing students. Nurses described being more aware of the importance of teaching EBP, which is similar to other research and demonstrates that participation in these opportunities enhances nurses' ability to apply evidence into their clinical practice. ${ }^{24-26}$

\section{Implications}

Our study findings have important implications for nurse leaders in their efforts to enhance therapeutic nurse-patient relationships through EBP implementation. Providing nurses the opportunity to engage in this work ensured alignment with the clinical area's priorities and allowed tailoring to the specific patient population. Leaders can acknowledge and use study findings around how nurses increased their awareness and assessment of patients' fears and anxieties. Specifically, study findings can be used in efforts to increase nurses' awareness of the complexity and multifaceted approach to care they undertake, while simultaneously highlighting the importance of an awareness of patients' condition beyond their immediate presentation, thus enhancing nurses' professionalism, knowledge, and care. Additionally, nurse leaders can use study findings in efforts to enhance interdisciplinary teamwork and nurses' confidence in being a key team member of this work to meet patients' individualized needs. Key to these efforts are ensuring opportunities exist to introduce EBP to new and existing staff, as well as student learners, and incorporating it into daily work and practice improvement initiatives. Further research needs to explore the patient perspective of these improvement efforts, and their impact on patient satisfaction and perceptions of quality and safety within an acute care setting.

While this study found two key themes, the following limitations should be noted. First, the cohort of study participants was drawn from one small respirology unit and study findings may not be transferrable to other clinical populations and health care settings. Second, data analyzed were from nurses' self-report of their experience with the implementation of BPG, which may not hold true in other settings. Third, our study involved nurses only, and did not include patients' views on their experience with the nursing care.

\section{Conclusion}

This study adds to the growing body of evidence around implementing EBP at the point of care. Study findings suggest that involvement in BPG implementation enabled nurses to address patients' fears and anxieties in a focused, conscientious manner, and to be more collaborative and confident in their care. Providing opportunities for nurses to learn and apply EBP around therapeutic patient-centered care is a key step in ensuring a quality patient experience. Continued investment from nurse leaders to enable nurses to employ EBP in their daily work is paramount.

\section{Acknowledgments}

This work is part of the RNAO BPSO ${ }^{\circledR}$ designation; for more information about the RNAO $\mathrm{BPSO}^{\circledR}$ program, visit www.rnao.ca.

\section{Disclosure}

The authors report no conflicts of interest in this work.

\section{References}

1. Institute of Medicine (US). Committee on Quality of Health Care in America. Crossing the Quality Chasm: A New Health System for the 21st Century. Washington, DC: National Academies Press, 2001. 
2. Dodek PM, Wong H, Heyland DK, et al; Canadian Researchers at the End of Life Network (CARENET). The relationship between organizational culture and family satisfaction in critical care. Crit Care Med. 2012;40(5):1506-1512.

3. Kohn LT, Corrigan JM, Donaldson MS. To Err is Human: Building a Safer Health System. Washington, DC: National Academy of Science, Institute of Medicine, 2002.

4. Spence Laschinger HK, Leiter MP. The impact of nursing work environments on patient safety outcomes: the mediating role of burnout/ engagement. J Nurs Adm. 2006;36(5):259-267.

5. Zarubi KL, Reiley P, McCarter B. Putting patients and families at the center of care. J Nurs Adm. 2008;38(6):275-281.

6. Díaz Del Campo P, Gracia J, Blasco JA, Andradas E. A strategy for patient involvement in clinical practice guidelines: methodological approaches. BMJ Qual Saf. 2011;20(9):779-784.

7. Vincent C, Davis R. Patients and families as safety experts. CMAJ. 2012;184(1):15-16.

8. Hasegawa T, Fujita S, Seto K, Kitazawa T, Matsumoto K. Patients' identification and reporting of unsafe events at six hospitals in Japan. Jt Comm J Qual Patient Saf. 2011;37(11):502-508.

9. King A, Daniels J, Lim J, Cochrane DD, Taylor A, Ansermino JM. Time to listen: a review of methods to solicit patient reports of adverse events. Qual Saf Health Care. 2010;19(2):148-157.

10. Albanese MP, Evans DA, Schantz CA, et al. Engaging clinical nurses in quality and performance improvement activities. Nurs Adm Q. 2010; 34(3):226-245.

11. Bjertnaes OA, Sjetne IS, Iversen HH. Overall patient satisfaction with hospitals: effects of patient-reported experiences and fulfillment of expectations. BMJ Qual Saf. 2012; 21(1):39-46.

12. Bitzas V, Calestagne PP, McVey L, Lapointe B. Encouraging patients and families to influence change on a palliative care unit value of patient satisfaction surveys. J Nurs Care Qual. 2011;26(4):350-357.

13. Ponte PR, Conlin G, Conway JB, et al. Making patient-centered care come alive: achieving full integration of the patient's perspective. J Nurs Adm. 2003;33(2):82-90.

14. Putman-Casdorph H, McCrone S. Chronic obstructive pulmonary disease, anxiety, and depression: state of the science. Heart Lung. 2009;38(1):34-47.
15. Kelly C, Lynes K. Psychological effects of chronic lung disease. Nurs Times. 2008;104(47):82-85.

16. Kellerman J, Zeltzer L, Ellenberg L, Dash J, Rigler D. Psychological effects of illness in adolescence. I. Anxiety, self-esteem, and perception of control. J Pediatr. 1980;97(1):126-131.

17. Gayton WF, Friedman SB, Tavormina JF, Tucker F. Children with cystic fibrosis: I. Psychological test findings of patients, siblings, and parents. Pediatrics. 1977;59(6):888-894.

18. Brissette S, Zinman R, Fielding M, Reidy M. Nursing care plan for adolescents and young adults with advanced cystic fibrosis. Issues Compr Pediatr Nurs. 1987;10(2):87-97.

19. Ritchie L, Prentice D. An exploration of nurses' perceptions regarding the implementation of a best practice guideline on the assessment and management of foot ulcers for people with diabetes. Appl Nurs Res. 2011;24(2):88-93.

20. Millman EA, Pronovost PJ, Makary MA, Wu AW. Patient-assisted incident reporting: including the patient in patient safety. J Patient Saf. 2011;7(2):106-108.

21. Iedema R, Allen S, Britton K, Gallagher TH. What do patients and relatives know about problems and failures in care? BMJ Qual Saf. 2012;21(3):198-205.

22. Lacey SR, Olney A, Cox KS. The clinical scene investigator academy: the power of staff nurses improving patient and organizational outcomes. J Nurs Care Qual. 2012;27(1):56-62.

23. Jeffs L, Beswick S, Lo J, Campbell H, Byer C, Ferris E. Hospital nurses' perceptions associated with implementing multiple guidelines: a qualitative study. J Nurs Edu Prac. 2013;3(2):31-40.

24. Dyess $S$, Sherman R. Developing the leadership skills of new graduates to influence practice environments: a novice nurse leadership program. Nurs Adm Q. 2011;35(4):313-322.

25. Jeffs L, Smith O, Wilson G, et al. Building knowledge for safer care: nursing research advancing practice. J Nurs Care Qual. 2009;24(3): 257-262.

26. Kramer M, Maguire P, Halfer D, et al. The organizational transformative power of nurse residency programs. Nurs Adm Quart. 2012;36(2): $155-168$.
Nursing: Research and Reviews

\section{Publish your work in this journal}

Nursing: Research and Reviews is an international, peer-reviewed, open access journal publishing original research, reports, reviews and commentaries on all aspects of nursing and patient care. These include patient education and counselling, ethics, management and organizational issues, diagnostics and prescribing, economics and

\section{Dovepress}

resource management, health outcomes, and improving patient safety in all settings. The manuscript management system is completely online and includes a very quick and fair peer-review system. Visit http://www.dovepress.com/testimonials.php to read real quotes from published authors. 